\title{
Bienestar emocional y el docente: un diario creativo en emociones
}

\author{
Emotional Well-Being and the Teacher: A Creative Journal on Emotions
}

\section{O bem-estar emocional e o professor: um diário criativo sobre as emoções}

\author{
Arely González Pérez \\ Benemérita Universidad Autónoma de Puebla, México \\ Universidad de los Ángeles, México \\ arely.gonzalez@correo.buap.mx \\ https://orcid.org/0000-0002-5469-4832
}

\section{Resumen}

A raíz de la pandemia por la covid-19 y las medidas sanitarias tomadas por las autoridades educativas para desacelerar el número de contagios, entre ellas la educación desde casa, uno de los temas que se posicionó en el centro de interés fue el de las emociones. Particularmente, al enfrentarse a nuevas condiciones de vida, de trabajo, de transmisión de conocimientos a los estudiantes, los docentes comenzaron a ser más conscientes de su estado emocional y la manera en que afecta su desenvolvimiento tanto profesional como personal. El presente trabajo se propone indagar cómo está viviendo este momento de prolongada pandemia una muestra de docentes y estudiantes, analizar las emociones principales que están experimentado y crear un material de apoyo para el reconocimiento y manejo emocional. Esto a través de la investigación acción. Entre los resultados se encontró que el gremio docente requiere de tener herramientas que lo nutran para enfrentar los desafíos que se tienen por delante. Hay que considerar que la virtualidad es un área de oportunidad para hacer llegar a más personas el conocimiento, tal como sucedió con el producto de esta investigación, que terminó con una master class para los 80 sujetos de investigación y tiene casi 300 visitas en 


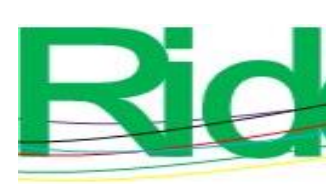

Revista Iberoamericana para la Investigación y el Desarrollo Educativo ISSN $2007-7467$

YouTube, además de un diario creativo para expresar emociones que se obsequió a los participantes.

Palabras clave: bienestar pedagógico, bienestar psicológico, emociones.

\section{Abstract}

As a result of the COVID-19 pandemic and the health measures taken by educational authorities to slow down the number of infections, including home schooling, one of the topics that was positioned in the center of interest was that of emotions. In particular, when facing new conditions of life, work, and transmission of knowledge to students, teachers began to be more aware of their emotional state and the way it affects their professional and personal development. The present work aims to find out how a sample of teachers and students is experiencing this time of prolonged pandemic, analyze the main emotions they are experiencing and create support material for emotional recognition and management. This through action research. Among the results, it was found that the teaching union requires having tools that nurture it to face the challenges that lie ahead. It must be considered that virtuality is an area of opportunity to make knowledge reach more people, as happened with the product of this research, which ended with a master class for the 80 research subjects and has almost 300 visits on YouTube and with a creative journal to express emotions that was given to the participants.

Keywords: pedagogical well-being, psychological well-being, emotions.

\section{Resumo}

Como resultado da pandemia covid-19 e das medidas de saúde tomadas pelas autoridades educacionais para diminuir o número de infecções, incluindo educação em casa, um dos tópicos que se posicionou no centro de interesse foi o das emoções. Em particular, ao se deparar com novas condições de vida, trabalho e transmissão de conhecimentos aos alunos, os professores passaram a ter mais consciência de seu estado emocional e da forma como ele afeta seu desenvolvimento profissional e pessoal. O presente trabalho tem como objetivo investigar como uma amostra de professores e alunos está vivenciando esse período de pandemia prolongada, analisar as principais emoções que estão vivenciando e criar material de apoio para o reconhecimento e manejo emocional. Isso por meio da pesquisa-ação. Dentre 


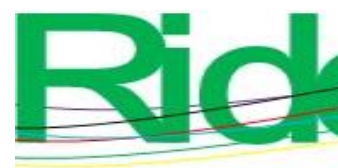

Revista Iberoamericana para la
Investigación y el Desarrollo Educativo
ISSN $2007-7467$

os resultados, constatou-se que o sindicato docente requer ferramentas que o nutram para enfrentar os desafios que se avizinham. Deve-se considerar que a virtualidade é uma área de oportunidade para fazer com que o conhecimento chegue a mais pessoas, como aconteceu com o produto desta pesquisa, que terminou com uma master class para os 80 sujeitos da pesquisa e tem quase 300 visitas no YouTube. a um diário criativo para expressar as emoções que foi transmitido aos participantes.

Palavras-chave: bem-estar pedagógico, bem-estar psicológico, emoções.

Fecha Recepción: Febrero 2021

Fecha Aceptación: Septiembre 2021

\section{Introducción}

A raíz de la pandemia por la covid-19 y las medidas sanitarias tomadas por las autoridades educativas para desacelerar el número de contagios, entre ellas la educación desde casa, uno de los temas que se posicionó en el centro de interés fue el de las emociones. Particularmente, al enfrentarse a nuevas condiciones de vida, de trabajo, de transmisión de conocimientos a los estudiantes, los docentes comenzaron a ser más conscientes de su estado emocional y la manera en que afecta su desenvolvimiento tanto profesional como personal.

¿Por qué adentrarnos en las emociones de los docentes? Porque mucho se habla de lo que viven los alumnos, más se deja de lado al profesor. Las emociones son parte inherente de la vida y se convive con ellas hasta el último momento de existencia. De ahí que esta investigación indague sobre el bienestar emocional y psicológico en el docente y cuáles son las emociones que enfrenta en este momento de prolongada pandemia.

\section{Objetivos}

- Focalizar un grupo de alumnos y también docentes en ejercicio o funcionarios para verificar cómo están viviendo este momento de pandemia.

- Analizar las emociones principales que están presentes en este grupo de docentes.

- $\quad$ Crear un material que les apoye en el reconocimiento y manejo de sus emociones. 

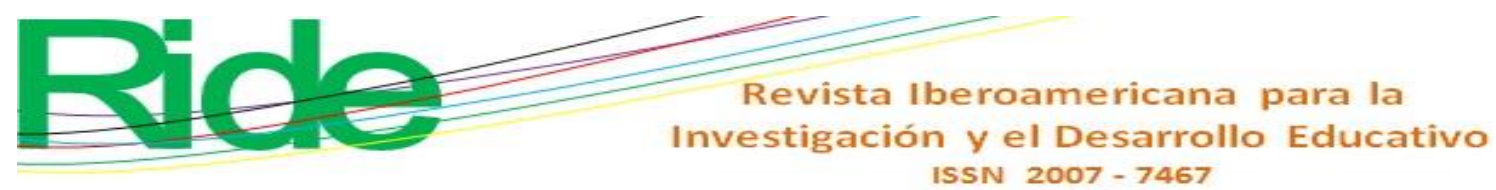

Una característica añadida por Aristóteles en relación con las emociones es que son experiencias acompañadas de placer (hedonēe y dolor (lupēe), porque se experimenta un ligero gusto o aversión como consecuencia de la emoción (Fonseca y Prieto, s. f.) Asimismo, Aristóteles (2016) hace referencia a la felicidad como una virtud que se acompaña de la prudencia y la sabiduría para lograr una vida completa. En consecuencia, los actos virtuosos son los árbitros de la felicidad. Cuando todo está en perfecta armonía, se conforma "cuadro sin reproche" (Aristóteles, 2016, p. 17). Cabe señalar que para Aristóteles (2016) el alma está dotada de una parte irracional y otra de un principio racional.

En relación con estos filósofos de la época clásica, Bisquerra, Pérez y García (2015) comentan:

Pensadores griegos como Hipócrates y Platón, más tarde Galeno, situaban parte o la totalidad de las funciones mentales (por entonces llamadas facultades del alma) en el cerebro. (...) El alma o ánima (etimológicamente aire, viento o soplo de vida), era inmortal e inmaterial y solo habitaba el cuerpo de forma provisional para dotarle de vida y regir su funcionamiento, en cambio pensaban que el cerebro era apenas una glándula que, aparte de tener un aspecto desagradable, debía tener poca funcionalidad. Sin embargo, el francés Descartes (1649) llegó a sugerir que el alma se situaba exactamente en una pequeña parte de la base del cerebro que había sido identificada por Galeno (p. 88).

Siguiendo a Bisquerra et al. (2015), en la tabla 1 se identifican las partes del alma y su ubicación en el cuerpo según Platón y Aristóteles (entre paréntesis se indica la virtud que se logra al dominar cada tipo de alma), (véase la tabla 1).

Tabla 1. Inteligencia emocional en educación

\begin{tabular}{|l|l|l|}
\hline \multicolumn{1}{|c|}{ Platón } & \multicolumn{1}{c|}{ Ubicación } & \multicolumn{1}{c|}{ Aristóteles } \\
\hline Racional (prudencia/sabiduría) & Cerebro & Intelectiva \\
\hline Irascible (fortaleza/valor) & Corazón & Sensitiva \\
\hline Concupiscible (templanza) & Vísceras/estómago/hígado & Vegetativa \\
\hline
\end{tabular}

Fuente: Bisquerra et al. (2015) 

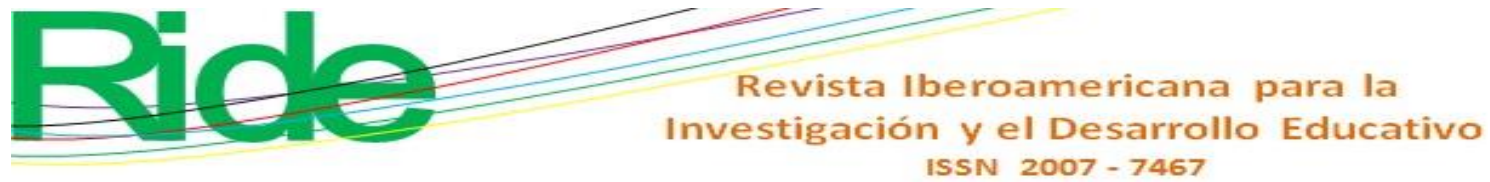

Ahora bien, lo que se muestra a continuación es un recorrido de las emociones desde la Grecia clásica hasta los estudios más recientes, entre estos la bioneuroemoción de Enric Corbera (véase la figura 2).

Figura 2. Cerebro y emociones un recorrido en la historia

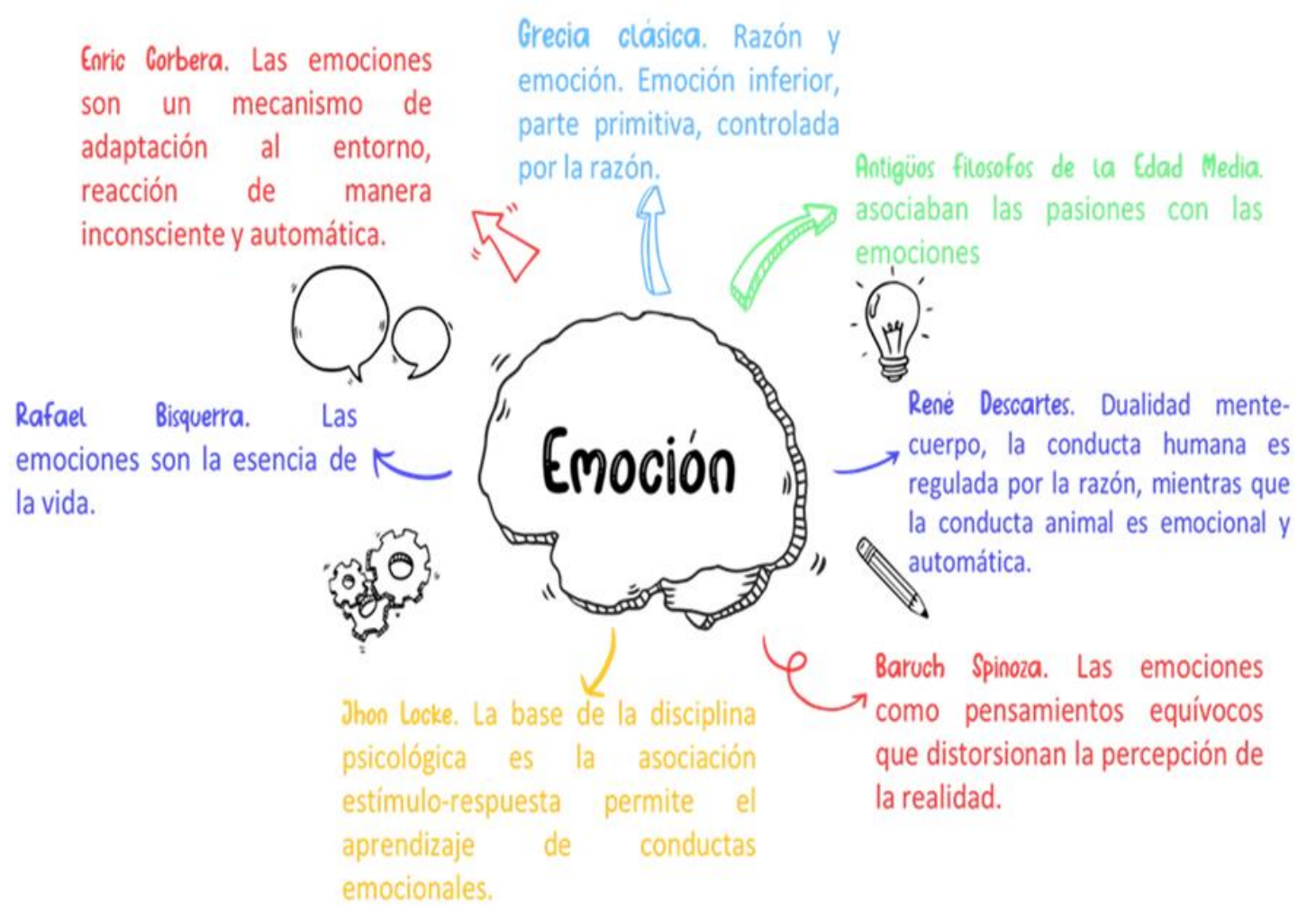

Fuente: Elaboración propia con base en Bisquerra et el. (2015) y Corbera (2017)

\section{Bienestar}

Claudia Esperanza Corredor Rojas (2016) resalta la importancia de reconocer el bienestar pedagógico como la valoración cognitiva y emocional del docente donde la felicidad, la sensación de plenitud, la autoestima, la motivación y la satisfacción por su trabajo, desempeño en el aula, influyen notablemente en sus niveles de bienestar.

Las emociones se presentan como respuesta personal a los acontecimientos de la vida del docente que constituyen la expresión de necesidades, la más importante es la de ser amados y reconocidos (...). Por lo tanto, un docente realizado, feliz, motivado, brindará un mejor ambiente educativo, sus métodos, estrategias, didácticas e innovaciones repercutirán en avances 


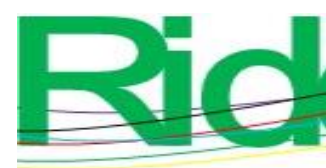

Revista Iberoamericana para la
Investigación y el Desarrollo Educativo
ISSN $2007-7467$

significativos para sus estudiantes (...). "Al mismo tiempo los docentes combinan su responsabilidad personal y su identidad profesional convirtiéndose el aula en el escenario principal donde se desarrolla su autoestima y realización personal pero también su vulnerabilidad" (Corredor, 2016, pp. 8-9).

Por su parte, Juan Dávila (2019) establece lo siguiente:

En las últimas décadas el constructo bienestar psicológico se ha convertido en uno de los conceptos fundamentales para la psicología positiva. Dicho constructo corresponde a la corriente filosófica del eudemonismo que nos entrega una visión de la experiencia humana en forma plena. Implica una persona que realiza actividades congruentes, tiene valores profundos y está comprometida con su funcionamiento óptimo.

Una de las principales investigadoras del bienestar psicológico es Carol Ryff, quien desarrolló el concepto centrando su atención en el desarrollo de capacidades para el crecimiento personal, las que a su vez se conciben como los principales indicadores del funcionamiento positivo de las personas (p. 7)

Asimismo, Dávila (2019) menciona que las características de funcionamiento individual presentes en las dimensiones del modelo de bienestar psicológico de Ryff delinean a una persona que se detiene a observar su desarrollo, a apreciar sus características tanto positivas como negativas, que posee una valoración positiva de su historia individual y que es capaz de anticiparse y comprometerse con nuevas metas para su crecimiento. Se exponen las dimensiones para lograr el bienestar psicológico (véase la figura 3). 


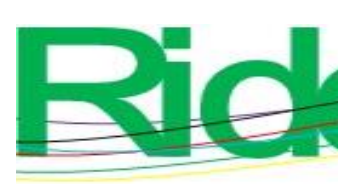

Revista Iberoamericana para la Investigación y el Desarrollo Educativo ISSN $2007-7467$

\section{Desentrañando la palabra emoción}

Como también explican Bisquerra et al. (2015), para conocer un poco más sobre el concepto de emoción vale la pena recurrir a su raíz etimológica. La palabra emoción procede del prefijo $e$ (variante del prefijo $e x$, que significa 'fuera') y del término motio ('movimiento'), y en conjunto significan 'mover' o 'movimiento hacia fuera'.

Otra palabra que acompaña a las emociones es la de motivación. Siempre se está mencionando lo importante que es motivar a los estudiantes dentro del aula, presencial o virtual. Al desentrañar también este término, Bisquerra et al. (2015) indican que procede de motivus (que significa 'motivo', 'que mueve o tiene virtud de mover') y del sufijo ción (acción o efecto), es decir, 'el motivo para la acción'. Así, la palabra emoción contiene los conceptos de fuera + movimiento, mientras que la palabra motivación contiene los de movimiento + acción. Emoción sugiere movimiento "hacia", mientras que motivación sugiere movimiento "para actuar" (Bisquerra et al., 2015, p. 153)

En suma, tomando en cuenta lo anterior, podemos decir que la motivación es provocar movimiento. Y dentro de la educación, emoción y motivación se pueden considerar como anverso y reverso de una misma moneda para consolidar el aprendizaje (Bisquerra et al., 2015, p. 139)

\section{¿Somos totalmente cerebrales?}

Néstor Braidot (2012) dice que todo está escrito en el cerebro: la capacidad de sentir y pensar, de emocionarnos y razonar, de aprender y memorizar, de enamorarnos y olvidar. También está inscrita la predisposición para agredir o conciliar, para perdonar o guardar rencor, para ganar o perder, para estar alegre o deprimido, para alcanzar el éxito o fracasar.

Por eso, el cerebro es un órgano que se debe "entrenar" y cuidar más que cualquier otro, (...) ya que, como bien explican los expertos a aquellos que imaginan escenarios en los que la ciencia hará todo lo que sea posible, "habrá trasplantes de corazón, de hígado, de pulmones, pero nunca habrá trasplantes de cerebro".

Esto se debe, en lo fundamental, a que la característica distintiva del cerebro es la neuroplasticidad, es decir, el fenómeno que hace que este órgano se vaya modificando a lo largo de la vida como respuesta a las condiciones medioambientales, el aprendizaje y a las experiencias que se van incorporando 

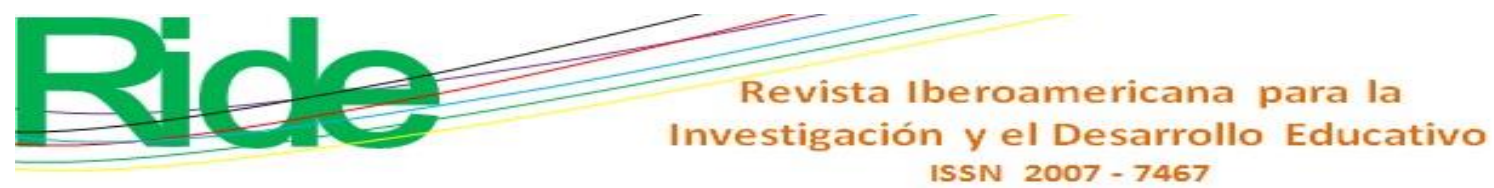

y, sobre todo, a lo que nosotros hacemos con esas experiencias (Braidot, 2012, p. 19)

\section{¿Cuál es el objetivo de sumar la neuroeducación a este proceso?}

Codina (2015) comenta que el objetivo de la neuroeducación, a diferencia de los objetivos de la neurociencia cognitiva y la neuropsicología, no es solo entender cómo los seres humanos aprenden mejor, sino también determinar la forma en que se les puede enseñar a maximizar su potencial. La novedad es que comienzan a estudiarse las bases cerebrales del proceso de enseñanza-aprendizaje, no solo del aprendizaje (Codina, 2015, pp. 16-17).

$\mathrm{Al}$ respecto, Jensen (2010) señala que el lado cognitivo del aprendizaje generalmente logra una gran cantidad de atención; mientras que, al ámbito de las emociones, el denominado lado afectivo, normalmente se le visualiza como una distracción para el aprendizaje. De hecho, algunas personas siguen creyendo que la enseñanza y las emociones están en extremos opuestos (Jensen, 2010, p. 103).

Tres descubrimientos en el ámbito de las emociones han cambiado nuestro modo de pensar sobre ellas. Primero, de las vías físicas y prioridades de las emociones. Segundo, los hallazgos sobre los componentes químicos del cerebro implicados en las emociones. Tercero, un vínculo entre estas vías y los componentes químicos con el aprendizaje y recuerdos cotidianos (Jensen, 2010, p. 104).

\section{Los diferentes tipos de emociones}

Si bien ha habido diversos intentos por realizar una sola tipología de las emociones, aún no se ha podido llegar a un consenso. Una de las clasificaciones más empleadas es la de distinguir entre emociones básicas y emociones complejas o secundarias. Las emociones básicas, también denominadas primarias, se reconocen por una expresión facial característica.

Las emociones básicas se inician con rapidez y duran unos segundos cada vez. Los investigadores discrepan en lo que concierne al número de ellas, pero en general se reconocen como tales: la alegría, la aflicción o tristeza, la ira, el miedo, la sorpresa y el asco. No existe cultura alguna de la que estén ausentes estas emociones. No son aprendidas, sino que forman parte de la configuración del ser humano. Esto se evidencia en la presencia de las mismas 

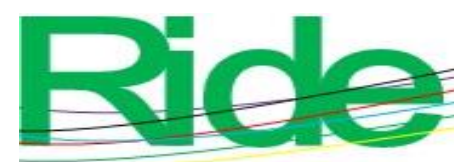

Revista Iberoamericana para la Investigación y el Desarrollo Educativo ISSN 2007 - 7467

expresiones faciales en los ciegos congénitos. Se pueden usar palabras o conceptos distintos para describir una determinada emoción, pero la expresión facial es la misma. Las emociones básicas están grabadas en los circuitos nerviosos de los genes y no a través de la cultura. Solo una vez activada la conciencia, transcurridos unos cientos de milisegundos, las reglas de exhibición culturalmente determinadas se imponen sobre la respuesta biológica elemental (Vivas, Gallegos y González, 2007, pp. 23-24).

\section{Metodología}

Evans (2010) indica que la investigación-acción promueve una nueva forma de actuar, inicia un esfuerzo de innovación y mejoramiento de la práctica docente que debe ser sometida permanentemente al análisis, evaluación y reflexión. La investigación-acción es un proceso en espiral de ciclos de investigación-acción que cuenta con las siguientes etapas: planificación, acción, observación y reflexión (Evans, 2010, p. 21). El paso a paso de la investigación acción: primero se debe realizar una planificación de lo que se realizará, para dar pie a la acción, observar los resultados y realizar una profunda reflexión. Una espiral de investigación (véase la figura 4).

Figura 4. Investigación-acción: el proceso

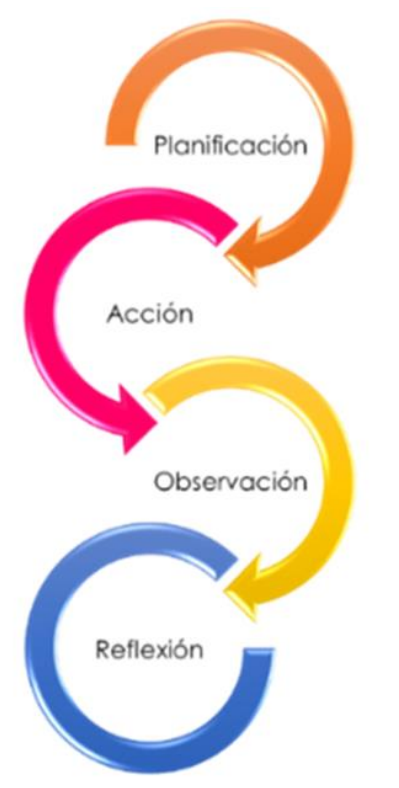

Fuente: Elaboración propia 

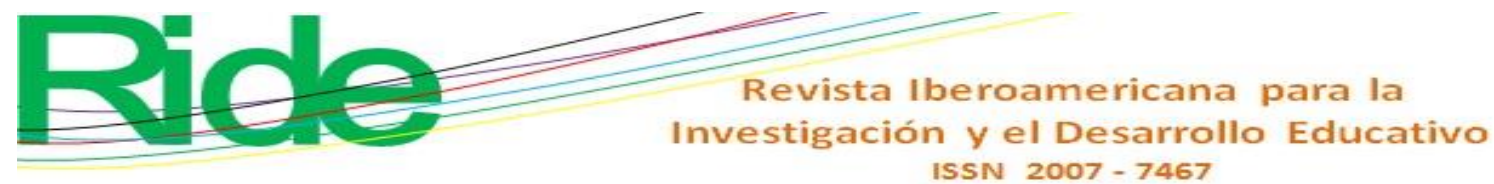

El método empleado para esta investigación es el de la investigación acción. Para ello, en primer lugar, se formuló la pregunta que guiaría todo el proceso, a saber: ¿cómo vive el docente sus emociones y cuál es la importancia de alcanzar el bienestar?

El instrumento aplicado es un documento de Google Forms (encuesta electrónica) que se aplicó antes para conocer la pertinencia del tema y después para la valoración de la master class que fue impartida (se detalla en el apartado de procedimiento y materiales).

Las respuestas se graficaron con ayuda del mismo instrumento, Forms, ya que cuenta con la función de trabajar las respuestas, procesarlas, presentarlas en gráficas y así facilitar el trabajo de investigación.

\section{Participantes}

Se contó con la participación de 80 alumnos en la Universidad de los Ángeles, campus Puebla, con un universo de tres grupos de maestría y tres de doctorado. Por las características que reúnen, son al mismo tiempo alumnos y se desempeñan como docentes o funcionarios educativos, (véase la tabla 2).

Tabla 2. Participantes del estudio

\begin{tabular}{|l|c|c|}
\hline \multicolumn{1}{|c|}{ Alumnos } & Total & Respondieron el Forms \\
\hline Maestría en Innovación Educativa & 50 & 44 \\
\hline Doctorado en Excelencia Docente & 40 & 36 \\
\hline
\end{tabular}

Fuente: Elaboración propia

\section{Procedimiento y materiales}

El proceso de investigación se planteó en dos etapas. En la primera etapa se aplicó un instrumento con 12 ítems, a través de Google Forms, ya que permite la construcción de preguntas e inserción de imágenes, lo cual resulta atractivo para los que responden. La invitación a llenar el instrumento se hizo llegar mediante correo electrónico. Contó con las siguientes preguntas: 
1) Género

2) ¿Está estudiando en este momento?

3) Me dedico a...

4) ¿Es importante el bienestar?

5) ¿Reconoce qué son las emociones y cómo intervienen en el aula?

6) ¿Cuántas emociones existen?

7) ¿Aplica estrategias didácticas para fomentar el bienestar en el aula o lugar de trabajo?

8) Estrategias didácticas para fomentar el bienestar en el aula:

9) ¿Sus emociones intervienen en el momento de dar clases?

10) ¿Qué emociones intervienen cuando da clases? Podrá elegir varias opciones, recuerde que son las que más prevalecen.

11) ¿Participaría en una master class que conjunte bienestar, aula y emociones?

12) ¿Qué tiempo dispondría para asistir a una master class o capacitación?

Los alumnos y alumnas de la maestría en Innovación Educativa y del doctorado en Excelencia Docente visualizaron en su celular u ordenador el Forms, que se construyó de manera atractiva, tanto las preguntas como las imágenes y color, (véase la figura 5 y 6 ). 


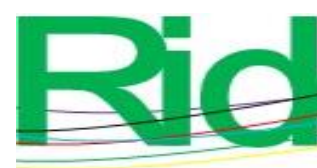

Revista Iberoamericana para la Investigación y el Desarrollo Educativo ISSN 2007 - 7467

Figura 5. Vista del instrumento Forms desde el celular

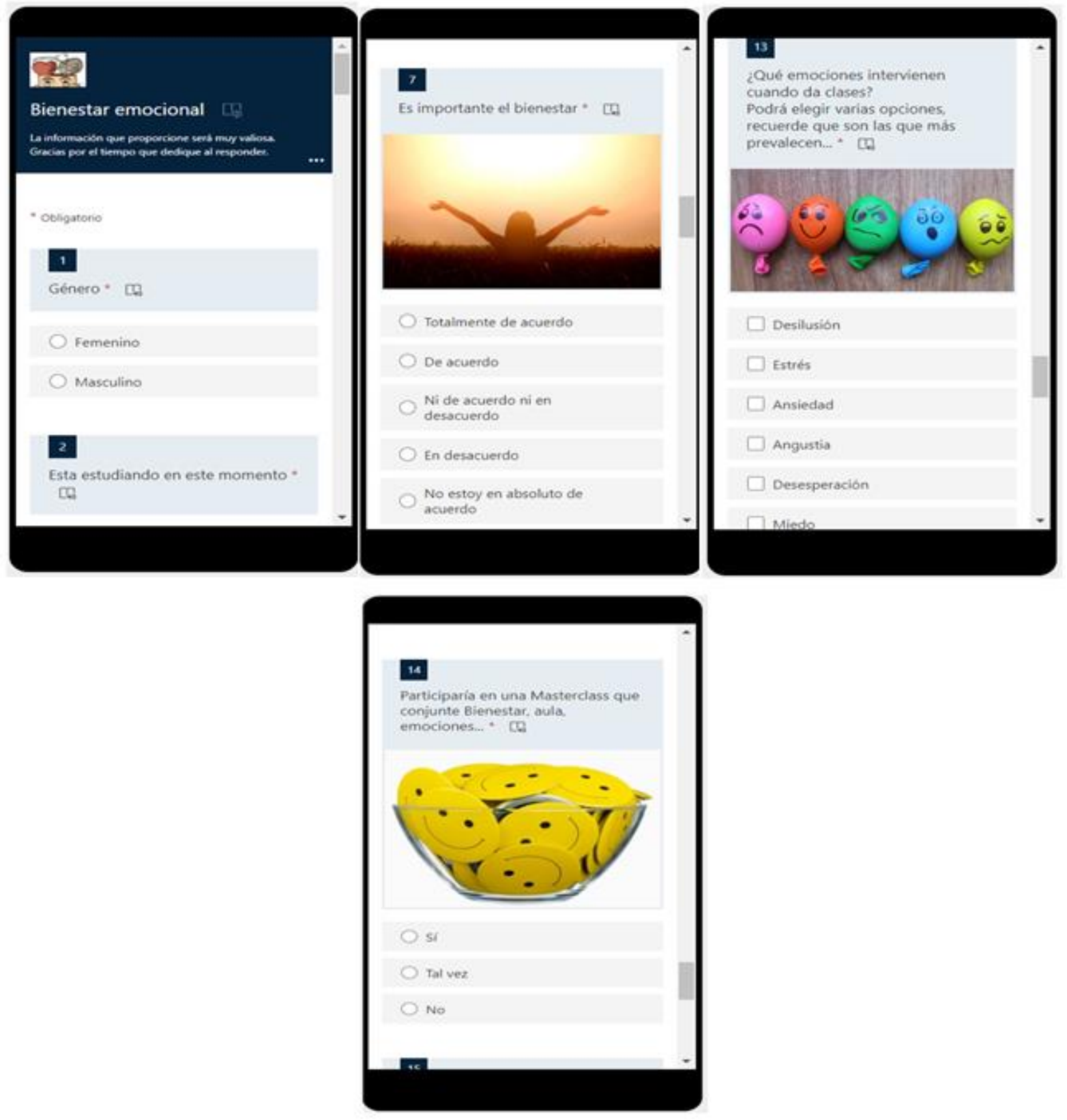

Fuente: Elaboración propia

En la segunda etapa se diseñó una master class y su instrumento de salida para su valoración, además de un diario creativo para expresar emociones, que se obsequió a los participantes. Todo lo anterior fue vía asíncrona, desde un canal de YouTube. 

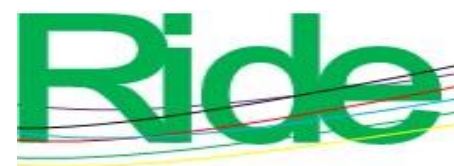

Revista Iberoamericana para la

Investigación y el Desarrollo Educativo

ISSN 2007 - 7467

Figura 6. Vista del instrumento Forms desde la computadora
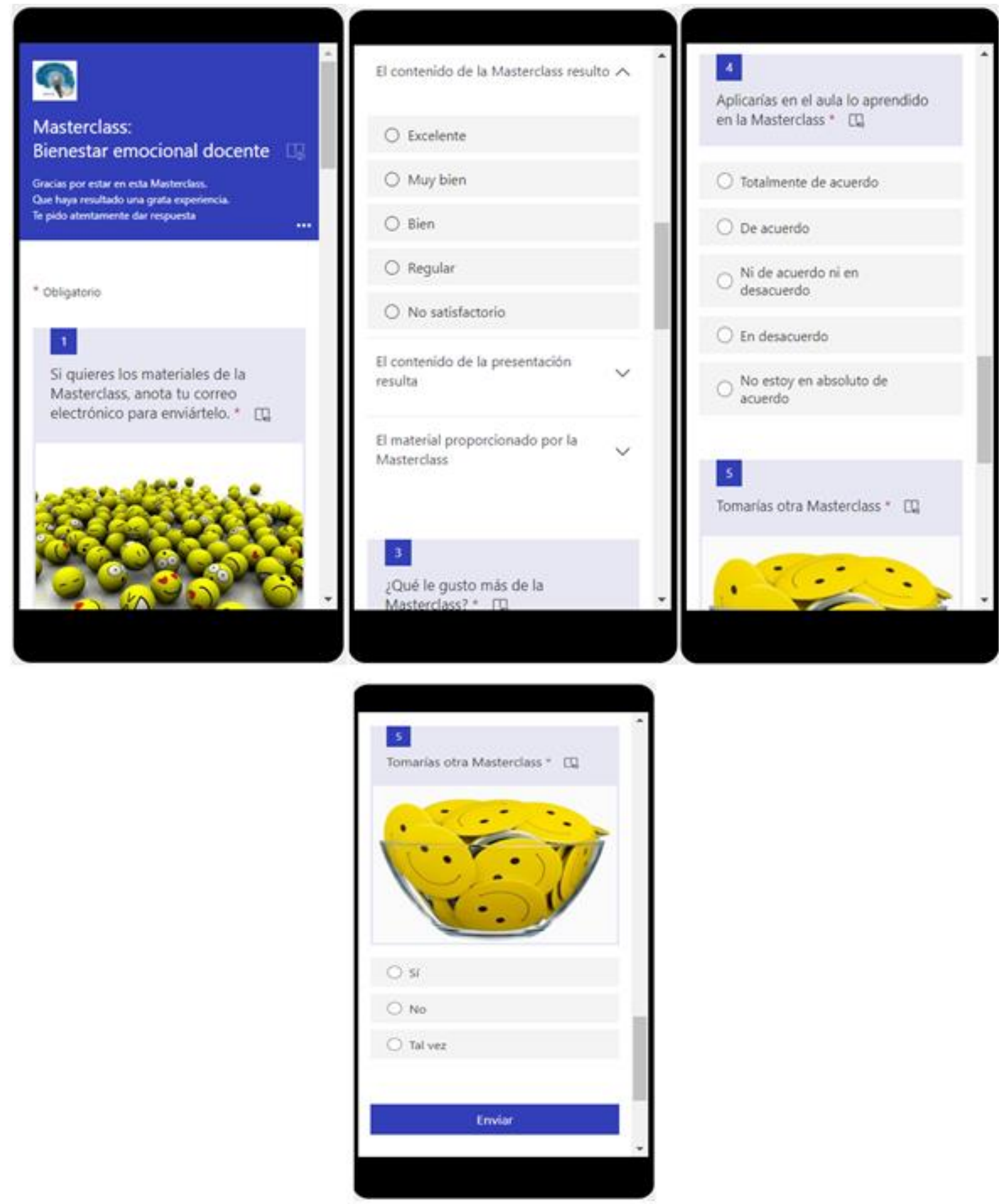

Fuente: Elaboración propia 


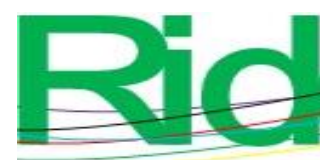

Revista Iberoamericana para la Investigación y el Desarrollo Educativo ISSN 2007-7467

\section{Resultados}

Del instrumento Forms de inicio se obtuvieron las siguientes gráficas, iniciando con el género de cada uno de los participantes tal como se muestra a continuación, (véase la figura 7).

Figura 7. Género

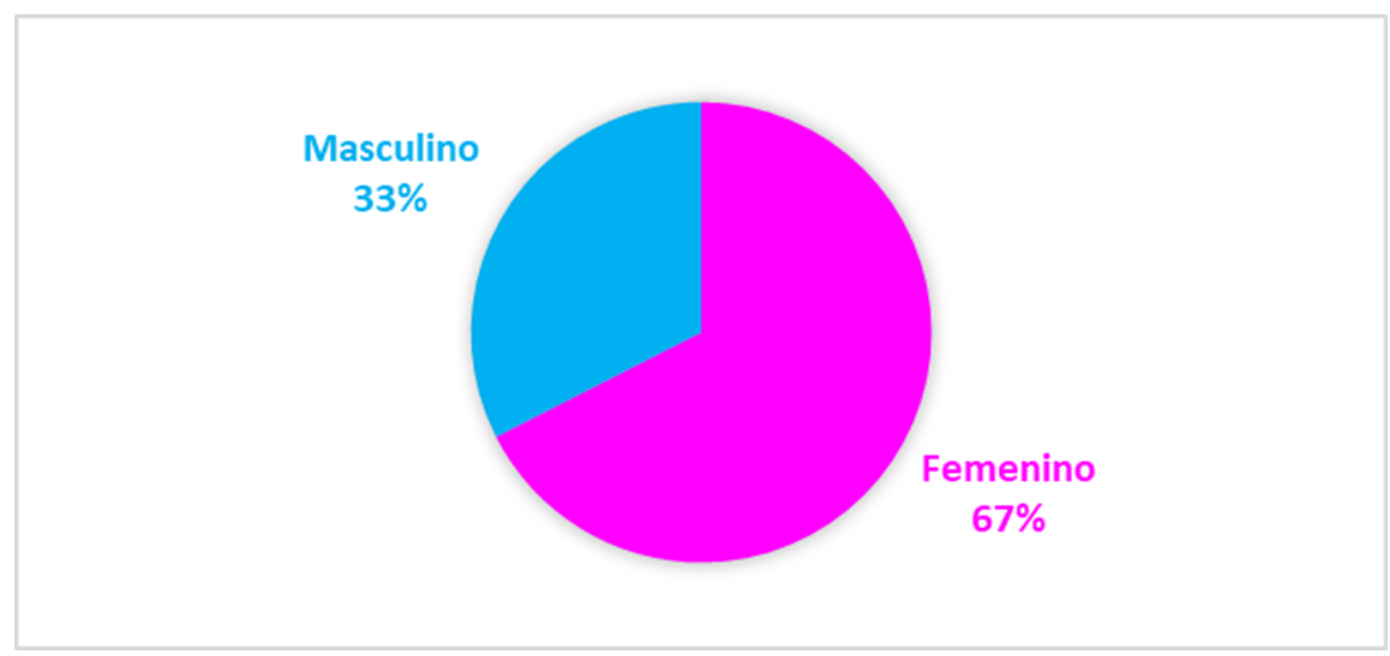

Fuente: Elaboración propia

La presencia del género femenino prevalece en áreas de formación educativa en la Universidad de los Ángeles, campus Puebla, o al menos así lo indica la muestra de este estudio.

Figura 8. ¿Está estudiando en este momento?

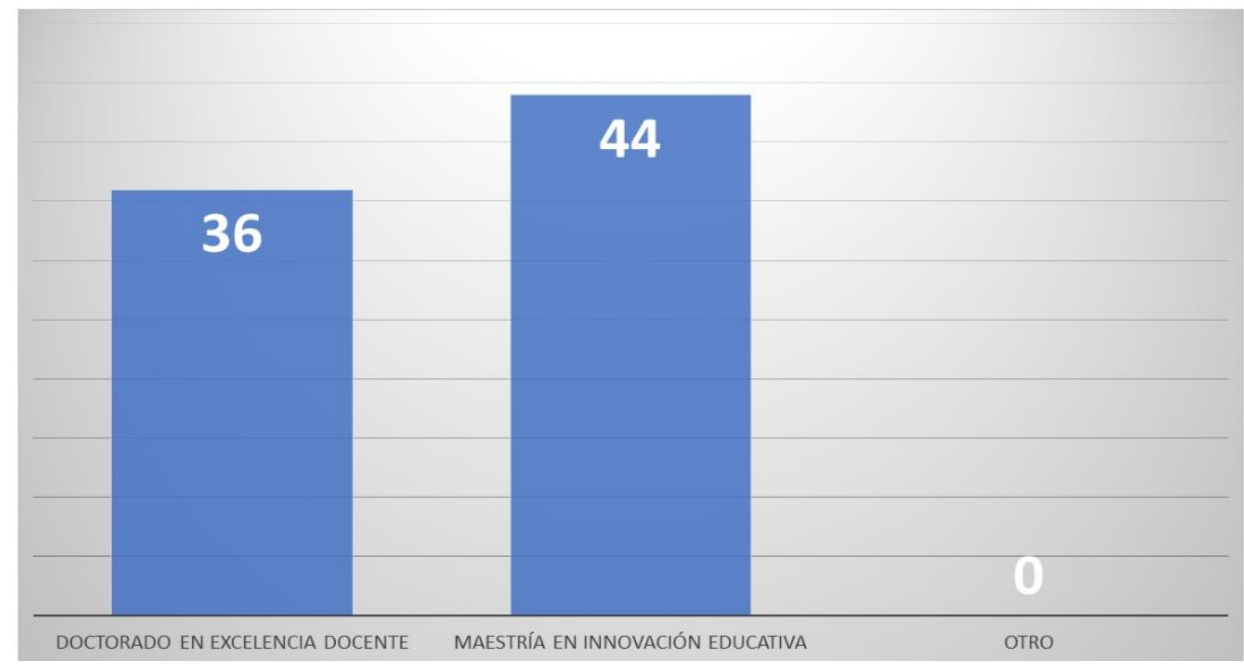

Fuente: Elaboración propia 


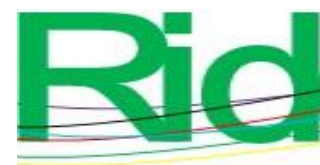

Como se aprecia en la figura 8 la mayoría de los estudiantes respondió el formulario; quienes no lo hicieron fue por presentar síntomas de covid-19, estar saliendo de la enfermedad o en cuarentena (véase la figura 8).

Figura 9. Me dedico a...

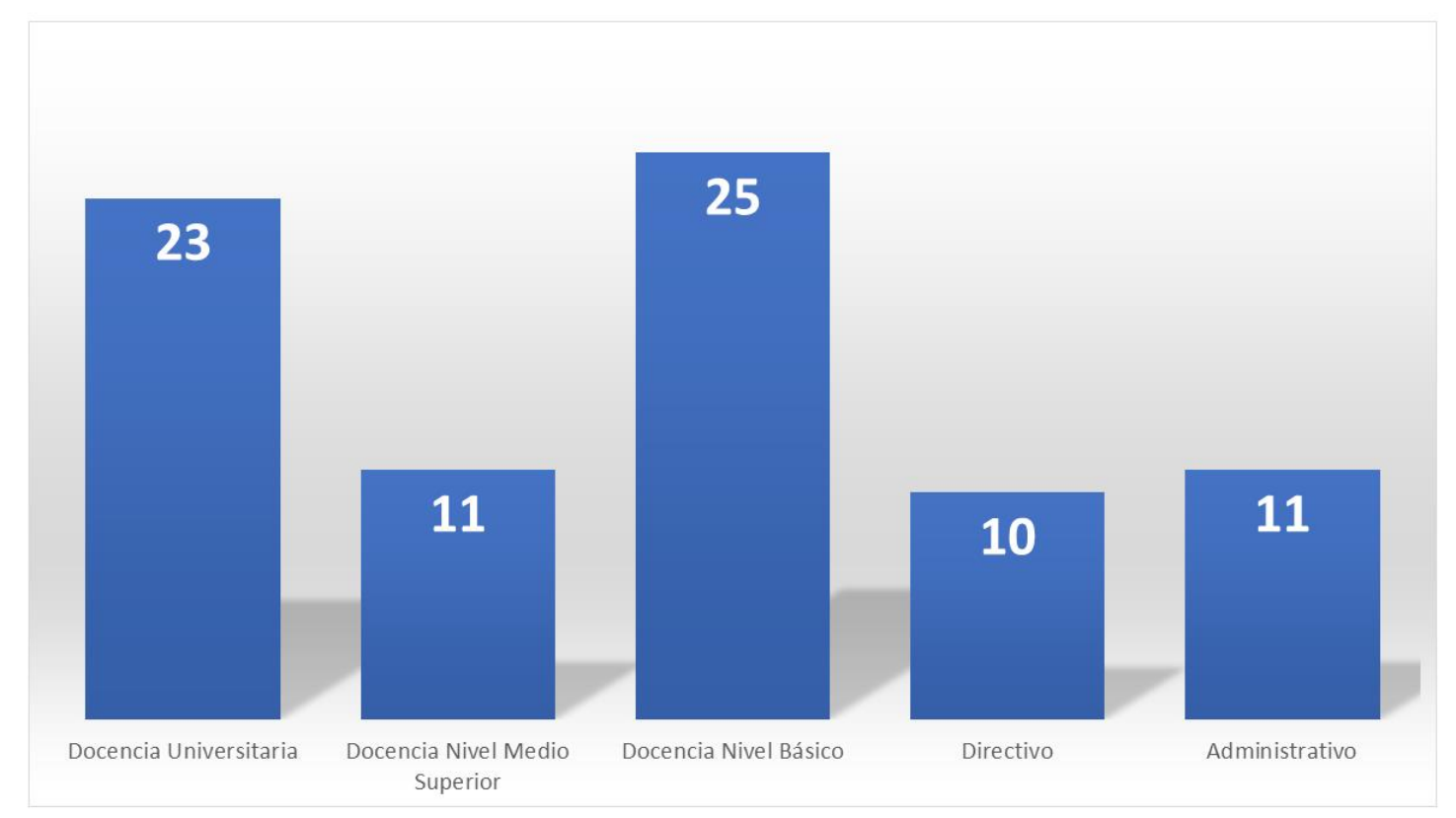

Fuente: Elaboración propia

Se destaca la población que participó se dedica mayormente a la docencia en el nivel básico, seguido por la docencia a nivel universitario, administrativos y directivos (véase la figura 9). 

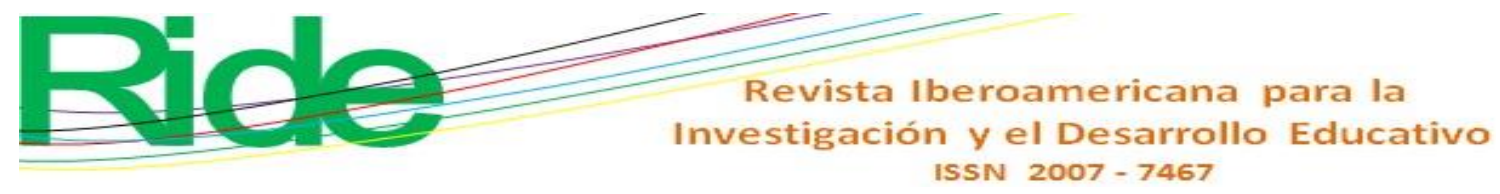

Se observa que la mayoría responde que sí aplica estrategias, aunque sea algunas veces. En el polo opuesto, siete participantes respondieron que no (véase la figura 13).

$\mathrm{Y}$ entre esas estrategias didácticas para fomentar el bienestar en el aula, se especificaron las siguientes:

- $\quad$ Asertividad y empatía.

- $\quad$ Escucha activa.

- Sana convivencia.

- $\quad$ Estrategias de enseñanza.

- Motivación.

- $\quad$ Buena actitud ante los estudiantes.

- $\quad$ Emociones positivas.

- Juegos interactivos.

Figura 14. ¿Sus emociones intervienen en el momento de dar clases?

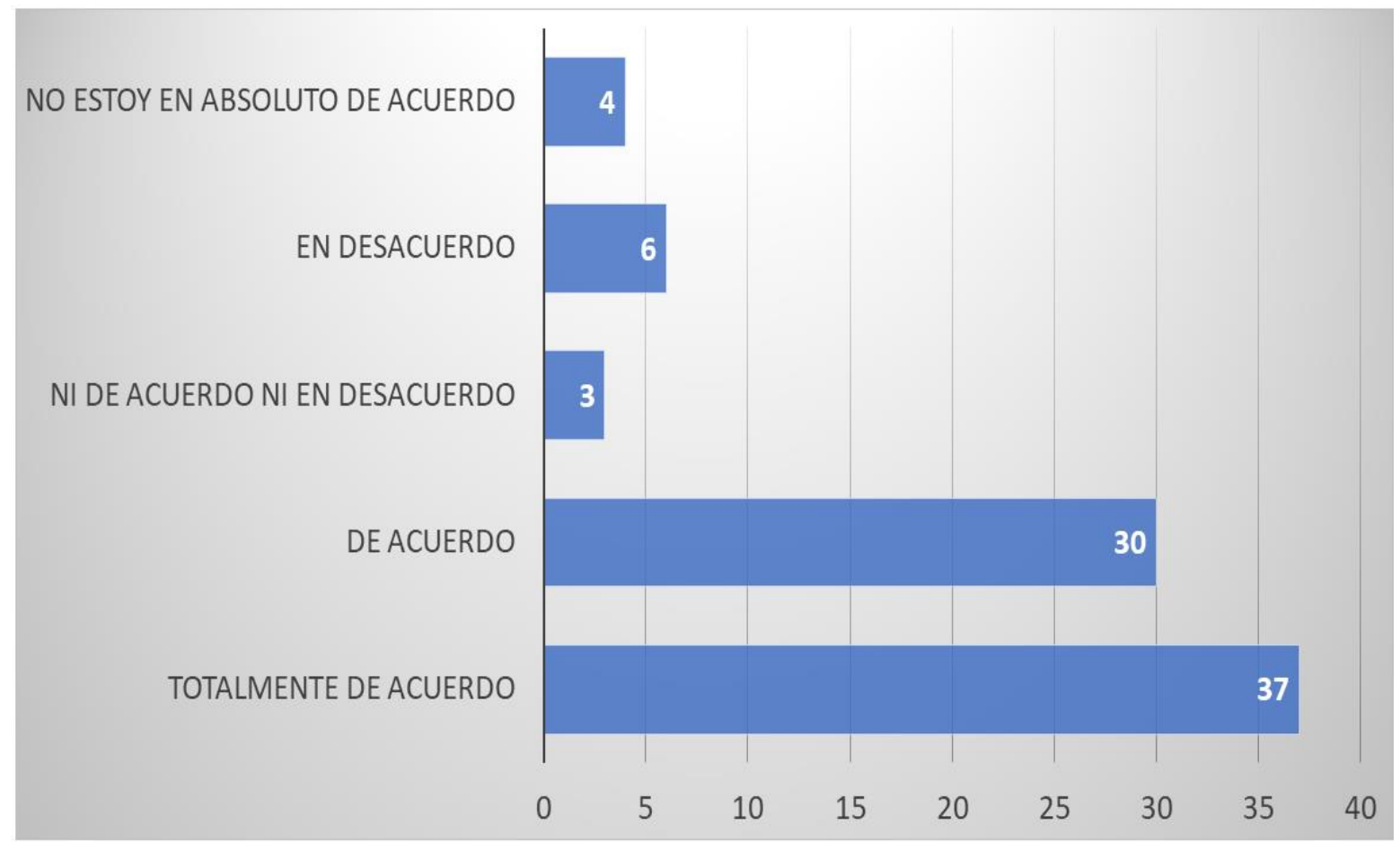

Fuente: Elaboración propia 


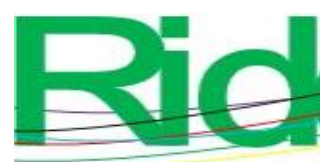

Revista Iberoamericana para la Investigación y el Desarrollo Educativo ISSN $2007-7467$

Figura 16. ¿Participaría en una master class que conjunte bienestar, aula y emociones?

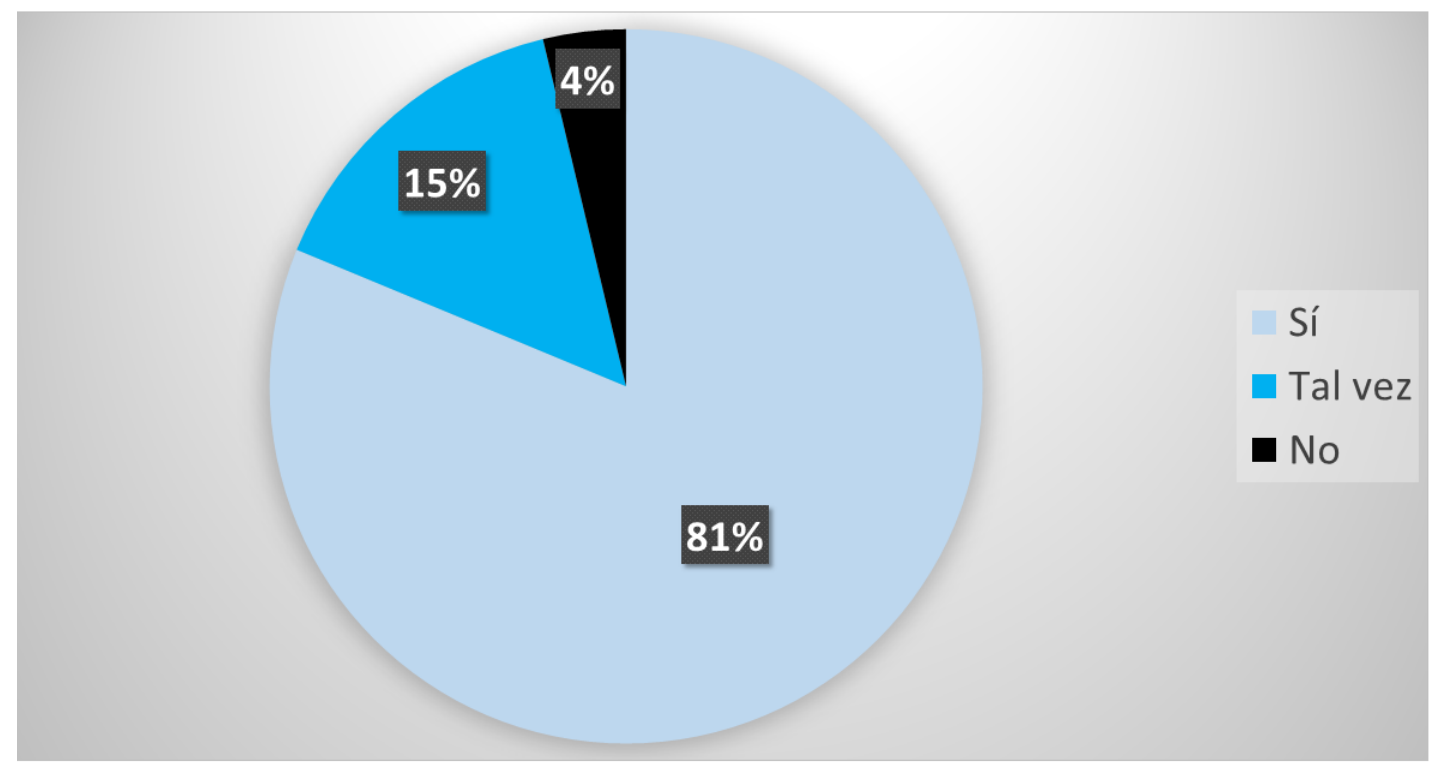

Fuente: Elaboración propia

Encontramos el fundamento para detonar la master class, ya que $81 \%$ de los sujetos de investigación respondió que sí participarían, contra 4 \% que indicó que no lo haría (véase la figura 16).

Figura 17. ¿Qué tiempo dispondría para asistir a una master class o capacitación?

\begin{tabular}{|c|c|}
\hline Minutos 30 & 8 \\
\hline Horas 1 & 30 \\
\hline Horas 2 & 14 \\
\hline Horas 3 & 7 \\
\hline Horas 4 & 2 \\
\hline Horas 5 & 5 \\
\hline Horas 6 & 3 \\
\hline Horas 10 & 5 \\
\hline Horas 20 & 6 \\
\hline
\end{tabular}

Fuente: Elaboración propia 


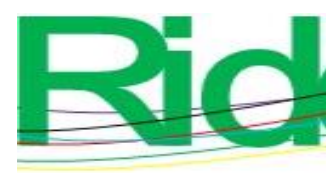

Revista Iberoamericana para la Investigación y el Desarrollo Educativo ISSN 2007 - 7467

Denotamos que los resultados obtenidos resultan contradictorios con lo visibilizado en el ítem nueve. Al final, los participantes coinciden en la importancia de las emociones, el reconocimiento y gestión de estas y piden hasta 30 horas de capacitación (véase la figura 17).

Como resultado de las emociones experimentadas por los participantes, se identifican, para un mejor trabajo y atención de cada una de ellas, sus características y gestión (véase la tabla 3).

Tabla 3. Emociones experimentadas por los que respondieron el Forms para esta investigación

\begin{tabular}{|l|l|}
\hline \multicolumn{1}{|c|}{$\begin{array}{c}\text { Emoción/ } \\
\text { identificación }\end{array}$} & \multicolumn{1}{|c|}{ Características } \\
\hline Estrés & $\begin{array}{l}\text { Es una descarga de adrenalina y de cortisol para responder a una } \\
\text { situación de urgencia o de presión (Jomard y Petitcollin, 2017, p. 5). }\end{array}$ \\
\hline Tensión & $\begin{array}{l}\text { Estado anímico de excitación, impaciencia, esfuerzo o exaltación } \\
\text { (Laymuns y Bisquerra, 2016, p. 135). }\end{array}$ \\
\hline Frustración & $\begin{array}{l}\text { Emoción que se experimenta cuando un obstáculo se interpone en el } \\
\text { camino y nos impide el logro de nuestros objetivos (Laymuns y } \\
\text { Bisquerra, 2016, p. 91). } \\
\text { Es desencadenada por un acontecimiento que se opone a nuestros } \\
\text { deseos (Ras, 2014, p. 18). }\end{array}$ \\
\hline Ansiedad & $\begin{array}{l}\text { Es una aceleración interna, una agitación nerviosa y palpitante. Dispara } \\
\text { las pulsaciones cardíacas de manera alarmante (Lomas, 2018, p. 47). }\end{array}$ \\
\hline Angobio & $\begin{array}{l}\text { Pérdida de la esperanza de conseguir algo que se desea, o de la ilusión } \\
\text { al saber que algo o alguien no es como se creía (Laymuns y Bisquerra, } \\
\text { 2016, p. 70). }\end{array}$ \\
\hline Desilusión & $\begin{array}{l}\text { Pérdida total de la esperanza. Alteración extrema del ánimo causada } \\
\text { por cólera, despecho o enojo (Laymuns y Bisquerra, 2016, p. 70). }\end{array}$ \\
\hline Temor opresivo sin causa precisa (Laymuns y Bisquerra, 2016, p. 48).
\end{tabular}



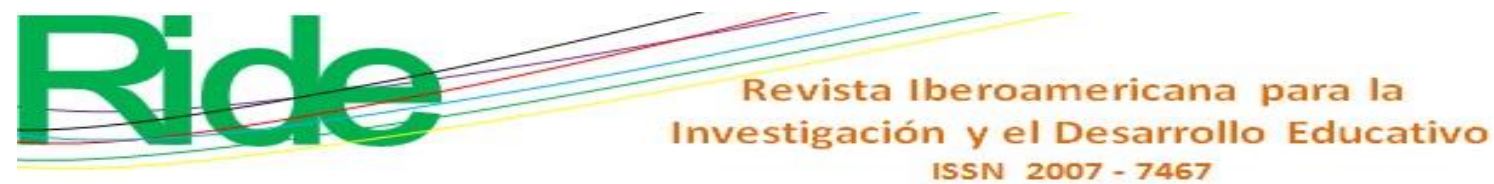

El diario creativo para expresar tus emociones es un referente, primero para los docentes, y luego para aplicarlo a los estudiantes, con algunas modificaciones de acuerdo con el nivel educativo. Se encuentra de manera digital en el siguiente enlace: https://es.calameo.com/read/006624258af9a58c3c23c

Retomando el tema de la master class, se verificó la asistencia por medio de un Forms de salida, es decir, después de verla en YouTube. Además, si deseaban el material en PDF con registro de Creative Commons, al dar respuesta dejaban su correo electrónico y a vuelta de correo electrónico lo obtuvieron, lo cual resultó muy atractivo.

Las respuestas fueron favorables a la actividad realizada y el formato resultó atractivo para quienes accedieron a él. Y el total de los participantes refirió que sí tomarían otra master class. El impacto de esta originó la asistencia del doble de participantes en un inicio, quienes recomendaron a su vez a otros participantes que la tomaran.

\section{Discusión}

En la master class se pensó en ir más allá con un material de apoyo entregable a los docentes, un diario creativo para expresar tus emociones, para que ellos, a su ritmo y sin interrumpir su tiempo, lo desarrollen. El diario tuvo una gran aceptación por parte de los docentes asistentes.

Entre los trabajos más cercanos al realizado aquí están el de Keri Smith (2015): Destroza este diario es un libro que resulta interesante, con muchos ejercicios, aunque no está orientado al trabajo en las emociones que presentan los docentes para su reconocimiento, gestión y trabajo de estas. Capacchione (2016), por su parte, aborda un diario creativo donde el arte ayuda a encontrarse; es una fuente de inspiración para el trabajo aquí realizado, por la formalidad de llevar un diario, y si bien los ejercicios propuestos son muy interesantes, no empatan del todo con los aquí llevados. Por fortuna, encontramos el trabajo de Llenas (2016), Diario de las emociones, que nos dio esta posibilidad de saber que estábamos en el camino correcto. El de Llenas (2016) es sin duda una fuente de inspiración para realizar el propio, con ejercicios orientados para los docentes grupo de estudio y todos aquellos que lo requieran. 


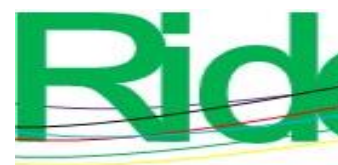

Revista Iberoamericana para la
Investigación y el Desarrollo Educativo
ISSN $2007-7467$

máxima, pues estamos aquí para ser felices. Es quizás unos de los puntos más complicados, encontrar la plenitud, y más en una ardua labor como la de la docencia, donde se entrega la vida y pocas veces se da el merecido reconocimiento. Huelga decir que a través del reconocimiento se construye el bienestar pedagógico.

Tercero, tratar de identificar cuál es la emoción y adaptarla a la acción que se debe realizar. También es necesario que consideres adaptarla a la situación para lograr los resultados esperados y alcanzar el bienestar (Dugay, 2017, p. 39). Y, por último, realizar los ejercicios necesarios a través del diario creativo para expresar tus emociones, ya que no siempre es sencillo lograr esta identificación y verse tal cual.

Cuarto, el reconocimiento de las emociones que emergen. Estas son parte de nosotros, hay que tomarlas como aliadas y aprender de ellas para crecer, expresarlas y tener un vocabulario más extenso en emociones.

Quinto, nuestros pensamientos y nuestras emociones están íntimamente relacionados. Un pensamiento puede provocar una emoción difícil como la ansiedad. Y, al revés, un estado de ansiedad puede igualmente hallarse en el origen de ciertos pensamientos negativos. Una particularidad de nuestros pensamientos es también que muchas veces son automáticos y repetitivos, por lo que deberemos practicar la plena conciencia y aprender a liberarnos de la esclavitud de los pensamientos negativos y atraer los positivos (Kotsou, 2014, p. 28).

Sexto, lograr la plenitud y el bienestar pedagógico y psicológico para el fortalecimiento del trabajo en las aulas y también en los alumnos. A cuidar de estos aspectos en un tiempo de emociones contradictorias.

Séptimo, aprender a vivir con plenitud la belleza de las emociones para lograr el bienestar (van Stappen, 2014, p. 46). El reconocimiento de las emociones que más están presentes en cada uno, cuál es la que tiene más arraigo, realizar un registro para saber si fortalece o debilita las acciones diarias, en el trabajo, en clases, con la familia. 


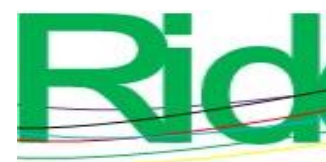

Revista Iberoamericana para la
Investigación y el Desarrollo Educativo
ISSN $2007-7467$

Futuras líneas de investigación

Una vez realizada la investigación se desprenden las siguientes líneas de investigación para considerar en un futuro:

- Incorporar la educación emocional en todos los niveles educativos para un mejor desarrollo psicoemocional.

- La psicología positiva como un área que debe explorarse con amplitud para reforzar los temas referentes al área socioemocional.

- Investigar a profundidad sobre el bienestar pedagógico y el impacto que tiene en el sector docente como una posibilidad para su crecimiento y fortalecimiento.

- Explorar la didáctica de las emociones, estrategias didácticas que conlleven emociones para trabajarlas en su identificación y gestión. Claro ejemplo, el diario creativo para expresar tus emociones, que está creciendo en actividades por el buen recibimiento que tiene y la necesidad de contar con un recurso como este para trabajar.

- Adentrarse a la filosofía de la educación para reforzar las áreas de estudio.

- Considerar en estos estudios a la neurociencia y el cerebro como el actor principal en los procesos educativos y, claro está, en las emociones.

- Analizar a futuro cuál es el impacto de las emociones en el organismo a través de la bioneuroemoción y la biodescodificación. Sin duda será sorprendente acercarnos y desentrañar la manera en que las emociones nos sanan y también nos enferman.

\section{Agradecimientos}

A la Universidad de los Ángeles, campus Puebla, por las facilidades prestadas para la presente investigación. 


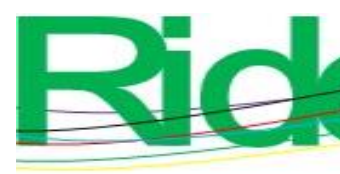

Revista Iberoamericana para la Investigación y el Desarrollo Educativo ISSN $2007-7467$

\section{Referencias}

Aristóteles. (2016). Ética nicomaquea Política. México: Porrúa.

Bisquerra, R., Pérez, J. C. y García, E. (2015). Inteligencia emocional en educación. Madrid, España: Síntesis.

Bisquerra, R. (2017). Universo de emociones (3. ${ }^{\text {a }}$ ed.). Valencia, España: PalauGea Comunicación.

Braidot, N. (2012). Sácale partido a tu cerebro. Argentina: Granica.

Capacchione, L. (2016). El diario creativo. El arte de encontrarte a ti mismo. Madrid, España: Gaia Ediciones.

Codina, M. J. (2015). Neuroeducación en virtudes cordiales. Barcelona, España: Octaedro.

Corbera, E. (2017). Bioneuroemoción. Un método para el bienestar emocional (1. a ed.). Barcelona, España: El Grano de Mostaza.

Corredor, C. E. (2016). Incidencias del bienestar pedagógico del docente en el rendimiento académico de los estudiantes de secundaria. (Tesis de maestría). Tecnológico de Monterrey, Bogotá. Recuperado de https://repositorio.tec.mx/bitstream/handle/11285/626473/Claudia_Esperanza_Corre dor_Rojas.pdf?sequence=7.

Dávila, J. (2019). Historias de bienestar: taller para docentes escolares. Iquique, Chile: Universidad de Tarapacá. Recuperado de http://eduinclusiva.cl/wpcontent/uploads/2019/04/Historias-de-bienestar_-Taller-para-docentes-escolaresHD.pdf.

Dugay, N. (2017). Cuaderno de ejercicios para desarrollar una mentalidad ganadora. Barcelona, España: Terapias Verdes.

Evans, E. (2010). Orientaciones metodológicas para la investigación-acción. Propuesta para la mejora de la práctica pedagógica. Perú: Ministerio de Educación. Recuperado de http://proyectosespeciales.upeu.edu.pe/wpcontent/uploads/2014/06/MINEDU-libro-orient_metod_investigacion-accionEVANS.pdf.

Fonseca, R. y Prieto, L. (s. f.). Las emociones y la retórica interpersonal desde los aportes de Platón y Aristóteles. Recuperado de https://docplayer.es/21441561-Las-emocionesy-la-retorica-interpersonal-desde-los-aportes-de-platon-y-aristoteles-rosariofonseca-de-rocca-leticia-prieto-de-alizo.html. 

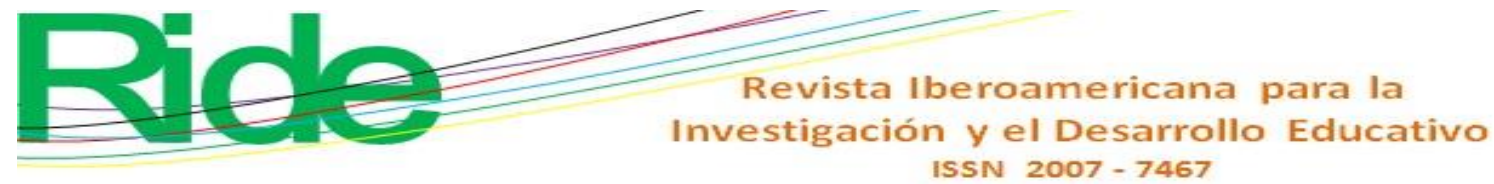

Jensen, E. (2010). Cerebro y aprendizaje. Competencias e implicaciones educativas. Madrid, España: Narcea.

Knuuttila, S. (2004). Emotions in Ancient and Medieval. New York, United States: Oxford University Press.

Kotsou, I. (2014). Cuaderno de ejercicios de plena conciencia. Barcelona, España: Terapias Verdes.

Laymuns, G. y Bisquerra, R. (2016). Diccionario de emociones y fenómenos afectivos. Valencia, España: PalauGea Comunicación.

Llenas, A. (2016). Diario de las emociones. México: Paidós.

Lomas, T. (2018). El poder positivo de las emociones negativas. Madrid, España: Urano.

Jomard, N. y Petitcollin, C. (2017). Cuaderno de ejercicios para organizarse mejor y vivir sin estrés. Barcelona, España: Urano.

Ras, P. (2014). Cuaderno de ejercicios de gestión de los conflictos. Barcelona, España: Terapias Verdes.

Sellés, J. F. (2010). Los filósofos y los sentimientos. Cuadernos de Anuario Filosófico, (227). Recuperado de https://dadun.unav.edu/bitstream/10171/36904/1/201502\%20CAF\%20227\%20(200) .pdf.

Smith, K. (2015). Destroza este diario. México: Paidós.

Thalmann, Y. A. (2014). Cuaderno de ejercicios para aprender a ser feliz. Barcelona, España: Terapias Verdes.

van Stappen, A. (2014). Cuaderno de ejercicios para evolucionar gracias a las personas difíciles. Barcelona, España: Terapias Verdes.

Vivas, M., Gallegos, D. y González, B. (2007). Educar las emociones (2. a ed.). Mérida, Venezuela: Producciones Editoriales. Recuperado de https://www.orientacionandujar.es/wpcontent/uploads/2016/05/libro_educar_emociones.pdf. 